\title{
O USO DE AGROTÓXICOS NA FLORICULTURA: O CASO DE VARGEM ALTA - REGIÃO SERRANA DO RIO DE JANEIRO
}

\section{The use of Agrochemicals in Floriculture: the case of Vargem Alta - Rio de Janeiro Mountainous Region}

\author{
Marilia Teresa Lima do Nascimento \\ Departamento de Geologia - UFF \\ marilianascimento@id.uff.br \\ Ana Dalva de Oliveira Santos \\ Departamento de Geologia - UFF \\ santosanadalva@gmail.com \\ Paulo Roberto Raposo Alentejano \\ Professor Associado da UERJ-FFP \\ paulinhochinelo@gmail.com \\ José António Baptista Neto \\ Departamento de Geologia - UFF \\ ineto@igeo.uff.br \\ Estefan Monteiro da Fonseca \\ Departamento de Geologia - UFF \\ oceano25@hotmail.com \\ Daniele Maia Bila \\ Faculdade de Engenharia - UERJ \\ danielebila@ueri.br
}

Artigo enviado para publicação em 07/08/2018 e aceito em 24/09/2018

DOI: $10.12957 /$ tamoios.2018.36593

\section{RESUMO}

A contaminação por agrotóxicos é uma das maiores preocupações ambientais e de saúde pública na atualidade. Os efeitos desses produtos atingem não só áreas rurais, mas a população como um todo. Vargem Alta, localizada na Região Serrana do Rio de Janeiro, possui tradição na produção de olerícolas e destaque no cultivo de flores como: crisântemos, rosas, palmas, tango, gérberas, entre outras. Este trabalho tem como objetivo avaliar os problemas de saúde por exposição aos agrotóxicos dos trabalhadores na floricultura. A metodologia consistiu na aplicação de um questionário específico para os agricultores, agentes de saúde e técnicos em Vargem Alta e adjacências, para obter dados sobre os principais sintomas relatados. Os resultados demonstraram expressiva utilização de agrotóxicos; fragilidade da fiscalização; descompasso entre as medidas mínimas de segurança; ausência de uso de equipamentos de proteção individual e descarte inadequado de embalagens. Entre os sintomas mais relatados destacam-se: problemas de nervos; endócrinos; neurológicos; respiratórios; hepáticos; alergias; hipertensão; diabetes; diarréias; dores no corpo e vertigens. Tais resultados na utilização de agrotóxicos, apontam para possíveis fatores de riscos ambientais e de saúde para os camponeses dessa área rural.

Palavras-chave: Agrotóxicos; Floricultura; Saúde

\begin{abstract}
The contamination by pesticides is one of the major enviromental and public health concerns in the present days. The effects of these products reach not only rural areas but also all the population. Vargem Alta, located in the mountains region of Rio de Janeiro has got a tradition in the production of olive groves and achieved a main position in the plantatio of flowers such as: chrysanthemums, roses, palms, tangos, gerberas etc. This work goals evaluate the health problems due to the floriculture workers exposition to pesticides. The methodology of this work consists of questionnaire application specific to farmers, health agents and technicians in Vargem Alta and adjacencies. The results demonstrated a substancially use of pesticides, fiscalization fragility, mismatch between minimal security actions; lack of individual protection usage and inadequate discard of packages. Among other symptoms we may highlight: nervous problems, endocrine, neurological, breath, hepatic, allergies, hypertension, diabetes, diarrhea, body aching and dizziness. These results are in the use of agrochemicals, point to variables of environmental and health areas for the peasants of this rural area.
\end{abstract}

Keywords: Pesticides; Floriculture; Health 


\section{INTRODUÇÃO}

Com o discurso de aumentar a produção de alimentos e erradicar a fome no mundo, desenvolveu-se a partir da segunda metade do século XX um modelo de produção na agricultura, intensivo em mecanização e uso de agrotóxicos, denominado de Revolução Verde. Isso promoveu a intensa geração e descarte de distintas substâncias químicas, sem um conhecimento prévio de seus efeitos ambientais (COLBORN et al., 2002; JALLOW et al., 2017). Assim, com promessa de facilitar a vida cotidiana, toneladas de substâncias são inseridas indiscriminadamente em todo o mundo, manipuladas por agricultores e consumidas pelas populações, e conseguintemente atingem os ecossistemas (CARSON, 1969; LI \& JENNINGS, 2018).

A significativa utilização de agrotóxicos, acentua-se com a hegemonia do modelo do agronegócio, baseado em grandes monoculturas. Esse modo de produção vem ocasionando uma série de transtornos e modificações em áreas rurais (ALENTEJANO, 2003) além de significativa contaminação nos ecossistemas (MOREIRA et al., 2002; MENDEZ et al., 2018). Tais fatores têm levado ao agravamento da contaminação humana e ambiental observado em várias matrizes como solo, ar, corpos hídricos, entre outros. Cabe citar que desde 2009 o Brasil se mantém em primeiro lugar no ranking mundial ne consumo de agrotóxicos (DOMINGUES, 2010; PELAEZ et al., 2010).

Importante considerar, que os pesticidas estão entre as substâncias químicas avaliadas com potencial estrogênico que representam riscos para animais e humanos. Tais compostos denominados desreguladores endócrinos, fazem parte da classe de contaminates que mesmo em concentrações muito baixas, na faixa de $\left(\mu \mathrm{g} \mathrm{L}^{-1} \mathrm{e} \mathrm{ng} \mathrm{L^{-1 }}\right)$ podem causar sérios efeitos danosos aos seres vivos (BILA \& DEZOTTI, 2007; NEGINTAJI et al., 2018). Desse modo, a preocupação a contaminação dos solos, ar e os recursos hídricos por distintas substâncias químicas como os agrotóxicos é bastante relevante. Atualmente publicações científicas vêm chamando atenção sobre o potencial desses compostos e os riscos ambiental (USEPA, 2008; BOGER et al., 2015). Essa preocupação é legítima, uma vez que o aumento expressivo dessas substâncias, seus subprodutos e metabólitos pode se desbobrar em outros produtos oriundos da degradação química e biológica dos compostos originais (LOCATELLI et al., 2016).

Os compostos químicos classificados como desreguladores endócrinos representam sérios riscos para répteis, pássaros, mamíferos e peixes por exemplo. Entre os efeitos atribuídos estão: diminuição na eclosão de ovos, problemas no sistema reprodutivo, imposex, feminização, masculinização, alterações no sistema imunológico, entre outros (PORSERYD et al., 2017; ABDEL-KHALEK et al., 2017). Em humanos, existem pesquisas que relacionam a doenças como as metabólicas, cardiovasculares, pulmonares, neuropsiquiátricas, neurodegenerativas, problemas de fertilidade e vários tipos de câncer (COLBORN et al., 1997; KIM et al., 2017).

O Programa de Análise de Resíduos de Agrotóxicos em Alimentos da Agência de Vigilância Sanitária (ANVISA) esclarece que partes consideráveis dos alimentos que chegam à mesa do consumidor, ou o índice do limite de agrotóxicos, está acima dos limites recomendados ou contaminados por produtos inapropriados (ANVISA, 2010). Nesse caso, os grandes prejudicados são os pequenos produtores rurais e a população em geral, porque os danos causados também atingem a população urbana (BOMBARDI, 2012). Desse modo, conciliar a produção livre de agrotóxicos e gerar relações mais justas é um enorme desafio a se transpor, no que se refere a resultados qualitativos e quantitativos tanto para os produtores, quanto para os consumidores (OLIVEIRA-SILVA et al., 2001).

Em relação ao consumo de agrotóxicos especificamente na floricultura, as informações são bem mais escassas do que as citadas para produção de olerícolas, por exemplo (TAMAI et al., 2000). Não obstante, devido à fragilidade das flores, a utilização de agrotóxicos é bastante significativa em todas as fases de produção, seja na fertilização, transplante, pulverização, corte 
e embalagem das flores. Segundo Rodrigues et al. (2010) embora estejam disponíveis no Brasil diversos produtos para o controle de pragas e doenças, poucos são recomendados para uso na floricultura, o que se constitui um sério problema a ser enfrentado pelos produtores. Entretanto, como esclarecem os autores o uso de substâncias químicas é expressivo durante todas as fases de produção (RODRIGUES et al., 2010)

Nesse sentido, este trabalho tem como objetivo avaliar os problemas de saúde dentro da abordagem geográfica, relacionados à exposição por agrotóxicos na produção de flores em Vargem Alta, região serrana do Rio de Janeiro. Mediante os resultados obtidos através das entrevistas a exposição aos agrotóxicos é bastante expressiva, sobretudo pela dificuldade no acesso a serviços básicos de saúde. Neste contexto, trabalhos que contribuam para elucidar a necessidade de melhoria nos indicadores de saúde e cuidados nessas áreas são pertinentes, no que se refere aos agravos para a população exposta (KASSOUF, 2005).

\section{MATERIAIS E MÉTODOS}

A metodologia foi fundamentada na relevância das relações entre a Geografia e a Saúde, considerando estudos geográficos e análise da distribuição espacial das exposições na área de estudo. Segundo Iñiguez Rojas \& Toledo (1998) métodos e técnicas na investigação em saúde podem proporcionar novos conhecimentos para o estudo das relações espaciais nos processos saúde-doença e produzir resultados de valor prático para o bem-estar da população.

Nessa perspectiva, a metodologia utilizada incluiu, registros fotográficos e aplicação de um questionário específico para os 68 agricultores (as) de Vargem Alta e 42 para os das áreas no entorno, como Bocaina dos Blaudts e Benfica. Na Tabela 1 encontra-se o levantamento da exposição ocupacional e ambiental por agrotóxicos

Tabela 1. Levantamento da exposição ocupacional e ambiental por agrotóxicos

\begin{tabular}{|l|}
\hline 1- Identificação \\
\hline 2- Idade \\
\hline 6- Sexo \\
\hline 2- Estado civil \\
\hline 3- Escolaridade: \\
\hline 4- Relação de trabalho: • proprietário • empregado • meeiro • administrador • outros \\
\hline 5- Renda familiar \\
\hline 6- Quantos anos trabalho na agricultura \\
\hline 7- Idade que começou a trabalhar na agricultura \\
\hline 8- Quantas pessoas da sua família trabalham na agricultura \\
\hline 9- Alguém da família trabalha na aplicação de agrotóxicos \\
\hline 10- Quantas horas por dia são gastas na aplicação de agrotóxicos \\
\hline 11- Qual o tamanho da propriedade: \\
\hline 12- Quais flores foram plantadas nos últimos meses \\
\hline 13- Tenta diminuir o uso de agrotóxico no seu plantio \\
\hline 14- Conhece e utiliza o receituário agronômico \\
\hline 15- Recebeu treinamento sobre como usar agrotóxicos. \\
\hline 16- De quem recebeu a orientação para preparação e/ou aplicação de agrotóxico \\
\hline 17- Quem indica qual agrotóxico usar \\
\hline 18- De quem compra o agrotóxico \\
\hline 19- Entende o rótulo das embalagens e segue as recomendações contidas no rótulo \\
\hline 20- Quem recomenda o cálculo da dosagem do agrotóxico \\
\hline 21- Qual o lugar onde são armazenados os agrotóxicos \\
\hline 22- Após a aplicação do agrotóxico espera o tempo recomendado no rótulo para fazer a colheita? \\
\hline 23- Qual o destino das embalagens de agrotóxicos vazias \\
\hline 24- Você usa a embalagem do agrotóxico vazia para outro fim \\
\hline 25- Sua pele entra em contato com o agrotóxico \\
\hline
\end{tabular}




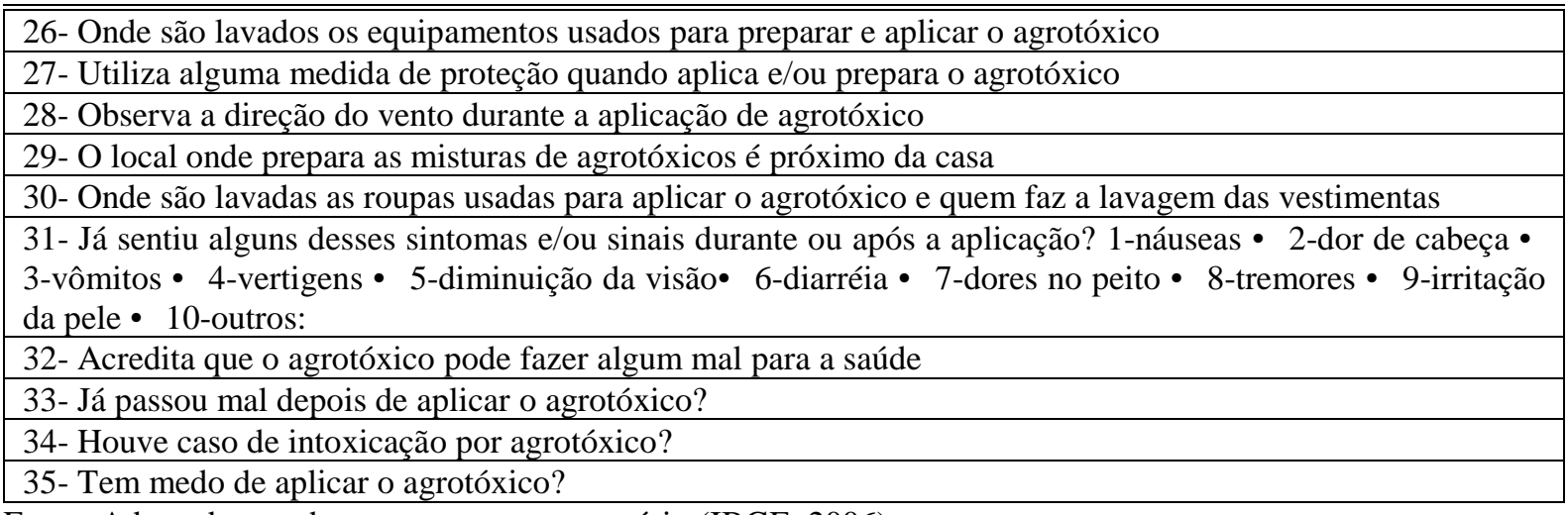

Fonte: Adaptado com base no censo agropecuário (IBGE, 2006)

Foram ainda entrevistados agentes de saúde e técnicos da Empresa de Assistência Técnica e Extensão Rural (EMATER) de Nova Friburgo. As entrevistas foram realizadas durante o período de 2007 a 2010, incluindo uma abordagem qualitativa, que permite o estudo de diferentes culturas e realidades, a partir da lógica dos próprios sujeitos, implicando na não neutralidade do pesquisador em suas observações (BAUER \& GASKELL, 2015).

\section{Área de Estudo}

A comunidade agrícola de Vargem Alta está localizada em São Pedro da Serra, $7^{\circ}$ distrito do Município de Nova Friburgo, região serrana fluminense. Situada a 170 quilômetros da cidade do Rio de Janeiro, sua base territorial é formada por terras desmembradas dos Distritos de Amparo e Lumiar, $4^{\circ}$ e $5^{\circ}$ distritos respectivamente, de Nova Friburgo. Abrangendo as localidades de São Pedro da Serra (sede do distrito) Benfica, Sibéria, Bocaina dos Blaudts, Vargem Alta, Pedra do Kaiser, Colonial 61 e Freimann. Apresenta uma extensão territorial de aproximadamente $64,5 \mathrm{~km}^{2}$ (PEREIRA, 2004). A região Serrana do Rio de Janeiro possui topografias muito íngremes e declividades desfavoráveis a cultivos de olerícolas. São Pedro da Serra, onde está inserida Vargem Alta, encontra-se em uma altitude que varia aproximadamente de 700 a 1.400 metros acima do nível do mar. Sua paisagem é exuberante, relevo irregular e montanhas alternadas com vales e pequenas várzeas, cortados por córregos e pequenos rios. A área agrícola se intercala com florestas secundárias e alguns trechos remanescentes da Mata Atlântica (SÁ REGO, 1988). Vargem Alta destaca-se pela produção de flores, embora exista paralelamente alguma produção de olerícolas.

A floricultura é uma atividade com múltiplas formas de exploração, como o cultivo de plantas ornamentais, flores e folhagens de corte, plantas envasadas e produção de sementes e bulbos. No início do século XX a floricultura brasileira constituía-se principalmente de cultivo de flores nos jardins e quintais residenciais, com função paisagística ou como decoração de interiores. A floricultura como atividade produtiva está diretamente relacionada às colônias de imigrantes holandeses, japoneses, alemães e portugueses. Mas, o pioneirismo é atribuído aos portugueses e alemães (CLARO et al., 1999). A produção de flores e plantas ornamentais nativas brasileiras tem características de uma atividade econômica desenvolvida por pequenos produtores distribuídos pelo território nacional, diversificados, produzindo desde flores e folhagens de corte e de vaso, mudas de plantas ornamentais para uso paisagístico e jardinagem, sementes e bulbos a flores e folhagens secas (CASTRO, 1992).

Segundo o Instituto Brasileiro de Floricultura (IBRAFLOR) no Estado do Rio de Janeiro, as principais áreas de produção estão localizadas na Região Metropolitana, dos municípios do Rio de Janeiro (com destaque para os bairros de Guaratiba, Jacarepaguá e Campo Grande). Em Niterói, São Gonçalo e Itaboraí, o destaque na produção são folhagens, flores de corte tropical e plantas para paisagismo. Na Região das Baixadas Litorâneas, como Saquarema, 
Médio Vale do Paraíba, Volta Redonda e Barra Mansa e Paraty, a produção é de plantas para jardim e folhagens tropicais. Na Região Serrana, nos municípios de Petrópolis, Teresópolis, Friburgo, Sumidouro e Bom Jardim, a produção é de rosas, crisântemos, gladíolos, gipsófila, cravos, lírios, antúrios, bromélias e plantas para jardins (CASTRO, 1992). Nova Friburgo especificamente destaca-se na produção de flores de corte como: rosas, crisântemos, palmas, chuvas de prata, tangos, copos de leite, e folhagens de corte (NEVES \& PINTO, 2015).

Dados apontam que a produção de crisântemos de Vargem Alta já é uma referência, sendo a segunda flor de corte mais comercializada, depois das rosas, tanto no Estado quanto no país (NEVES \& PINTO, 2015). Embora atualmente exista um contingente de mão de obra terceirizada, o trabalho é basicamente desenvolvido pelos camponeses. A maioria dos moradores têm algum parentesco entre si, nasceram e cresceram acompanhando as gerações anteriores trabalhando a terra (CARNEIRO, 2000). Dessa forma, o manejo do crisântemo tem se constituído em um dos segredos que os produtores de Vargem Alta dominam, sendo significativa essa produção para atender à demanda do mercado fluminense. Na Figura 1 encontra-se o Mapa da Localização de Vargem Alta, no distrito de São Pedro da Serra, município de Nova Friburgo.

Figura 1 -Mapa da localização da comunidade agrícola de Vargem Alta

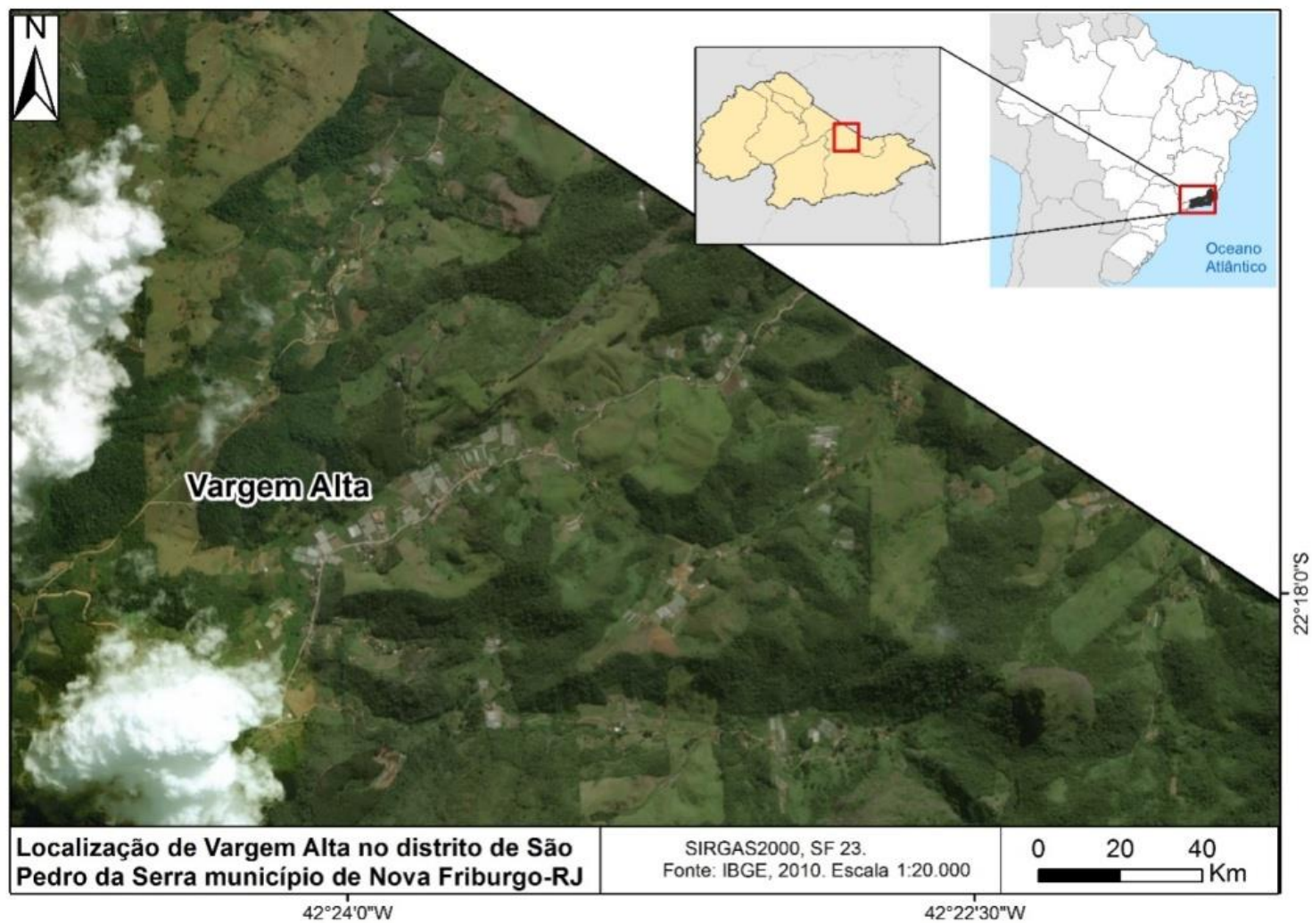

Fonte: Adaptado de IBGE, 2017.

\section{CONTEXTO HISTÓRICO DOS AGROTÓXICOS}

Desde os primórdios, a humanidade busca meios para aumentar a produção e disponibilidade de alimentos. Durante séculos, o desenvolvimento da agricultura foi marcado pela busca incessante da segurança alimentar. Assim, inúmeras técnicas foram criadas com o intuito de aumentar a produção, inclusive com o uso de produtos químicos (CHAIM, 1999; SILVA \& BOTELHO, 2014). O mais antigo registro da utilização de produtos na agricultura, remonta aos Sumérios, 2.500 (a.C.) que utilizavam enxofre para combater insetos. Outros 
indícios evidenciam a utilização de quantidades moderadas desses compostos por chineses, com o intuito de combater piolhos e outras pragas (BRAIBANTE \& ZAPPE, 2012). Os antigos romanos também se valiam da fumaça proveniente da queima do enxofre para combater insetos que atacavam suas lavouras (BARBOSA, 2004).

No final do século XIX e início do século XX, começaram a ser desenvolvidos inseticidas orgânicos sintéticos. O marco para o desenvolvimento de compostos orgânicos sintéticos foi a transformação do composto inorgânico cianato de amônio em uréia, um composto nitrogenado presente na urina e sua síntese foi executada pelo químico alemão Friedrich Wöhler em 1828. Nesse momento, acreditava-se que compostos orgânicos não poderiam ser sintetizados em laboratório e que eram produzidos apenas por organismos vivos (BARBOSA, 2004). O pesticida Dicloro-difenil-tricloroetano (DDT) foi descoberto em 1939 por Paul Müller, Quanto a sua classificação o DDT é um organoclorado. Possui alta letalidade e foi bastante usado no combate de doenças. Na década de 1940 os inseticidas sintéticos começaram a ser utilizados em larga escala, durante a Segunda Guerra Mundial, com a finalidade de proteção contra pragas transmissoras de doenças como malária, tifo, entre outras enfermidades (CARSON, 1969).

Entre outros inseticidas desenvolvidos nessa época, estão o Aldrin, Dieldrin, Heptacloro e Toxafeno (D'AMATO et al., 2002). Ambientalmente a periculosidade dos organoclorados consiste em sua insolubilidade em água e em sua solubilidade em líquidos apolares como éter, clorofórmio e em óleos e gorduras, o que colabora para o acúmulo no tecido adiposo dos organismos vivos. Outra séria ameaça é a alta estabilidade, levando anos para ser degradado na natureza devido à baixa reatividade das ligações químicas presente no composto em condições normais (WHO, 1990).

Outros compostos foram incorporados no controle de pragas, como os organofosforados e os carbamatos. A toxicidade aguda dos organofosforados é maior que a dos organoclorados, embora organofosforados apresentem menor persistência no ambiente e degradação mais rápida, levando a um número maior de aplicações. Logo, a grande problemática quanto ao uso e quantidades aplicadas reside no fato dos organismos desenvolverem resistência aos compostos, após certo tempo nas aplicações. Isso equivale a dizer, que o uso de agrotóxicos torna as pragas mais resistentes, levando a um círculo vicioso (CASTELO BRANCO, 2003).

Com o advento da Revolução Industrial e a necessidade de aumentar e aperfeiçoar a produção alimentar, em virtude do grande crescimento populacional, tornou-se uma meta para o atendimento direcionado para áreas urbanas. A saída encontrada foi a intensificação da produção agrícola através de novos maquinários e inserção de agroquímicos. A finalidade era combater ataques de pragas que costumavam destruir plantações inteiras, gerando problemas na disponibilidade de alimentos destinados à população em crescente expansão (CHAIM, 1999). Estas mudanças ocorreram primeiramente na Inglaterra, permitindo um fornecimento agrícola de aproximadamente $98 \%$ dos cereais consumidos por uma população duas a três vezes maior. Assim, estabelecia-se o uso de fertilizantes e maquinários para plantar colher e processar alimentos em grande escala (MAZOYER \& ROUDART, 2010).

A Revolução Verde, baseada no uso intensivo de fertilizantes sintéticos, promoveram nas atividades agrícolas uma grande transformação. Em grande parte, por avanços conseguidos na indústria química, desdobrando em profundos impactos no espaço geográfico no Brasil e no mundo (SANTOS, 1994). O amplo uso de agrotóxicos na agricultura ocorreu na maioria dos países do mundo e conseguintemente atingiu o Brasil, tanto em grandes plantações como em pequenas produções familiares. Desse modo, a utilização de agrotóxicos foi pautado em promessas de produções em larga escala e grandes lucros garantidos. Todavia, esse processo não passava de uma falácia, pois além da fome não ser erradicada, o que ficou de herança de impactos socioambientais e para a saúde no mundo todo (CARNEIRO et al., 2012). 
A contaminação química associada aos processos produtivos caracteriza-se como um dos mais complexos problemas de saúde pública e ambiental (PERES, 2009). O livro "Primavera silenciosa" de Rachel Carson já denunciava os efeitos adversos do uso do DDT, chamado de elixir da morte (CARSON, 1969). Dentro dessa realidade, a agricultura orgânica ou agroecológica pode representar uma estratégia frente às grandes propriedades agroexportadoras, como uma saída para a sustentabilidade ecológica e para a qualidade de vida (ALTIERI \& NICHOLLS, 2007).

\section{Definição dos Agrotóxicos}

Inúmeras denominações estão relacionadas a um grupo de substâncias químicas utilizadas no controle de pragas e doenças de plantas, tais como: agrotóxicos, defensivos agrícolas, pesticidas, praguicidas, remédios de planta e venenos (PERES \& MOREIRA, 2003). Esses compostos podem estar listados em quatro classes de acordo com os perigos que podem representar. Essa classificação é de acordo com o resultado dos testes realizados em laboratórios para obter a dosagem letal (DL), ou seja, $50 \%$ é a quantidade necessária de determinada substância para matar 50\% dos organismos testados em condições experimentais. A capacidade de determinada substância para causar morte ou algum efeito sobre os animais depende da sua concentração no corpo. A dose letal é expressa em miligrama da substância por quilograma da massa corporal (BRITO, 1994; WHO, 1990). Na Tabela 2 encontra-se a classificação toxicológica segundo a dose letal (DL).

A toxicidade de uma substância pode variar de acordo com o modo de administração, e os rótulos dos produtos são identificados por meio de faixas coloridas (PERES \& MOREIRA, 2003). Os agrotóxicos são definidos como produtos de natureza biológica, física ou química, podendo ser inorgânicos ou de origem orgânica. Diferenciar agrotóxicos em função da sua utilização, modo de ação e potencial toxicológico, aos seres vivos e ao ambiente, obedece a classificação segundo a ANVISA (2010) e o Ministério da Saúde, conforme Tabela 3.

Tabela 2 - Classificação toxicológica segundo a DL50

\begin{tabular}{ccc}
\hline Grupos & DL50 $(\mathbf{m g} / \mathbf{k g})$ & Dose mortal para adultos \\
\hline Extremamente tóxicos & 5 & 1 pitada - algumas gotas \\
Altamente tóxicos & $5-50$ & 1 colher de chá - algumas gotas \\
Medianamente tóxicos & $50-500$ & 1 colher de chá -2 colheres de sopa \\
Pouco tóxicos & $500-5000$ & 2 colheres de sopa -1 copo \\
Muito pouco tóxicos & $5000 \mathrm{ou}+$ & 1 copo -1 litro \\
\hline
\end{tabular}

Fonte: World Health Organization, 1990

Tabela 3 - Classificação Toxicológica dos Agrotóxicos

\begin{tabular}{|c|c|c|c|}
\hline Classe toxicológica & Toxicidade & DL50 (mg/Kg) & Cor da faixa \\
\hline I & Extremamente tóxicos & $\leq 5$ & Vermelha \\
\hline III & Altamente tóxicos & Entre 5 e 50 & Amarela \\
\hline III & Medianamente tóxicos & Entre 50 e 500 & Azul \\
\hline IV & Pouco tóxicos & Entre 500 e 5000 & Verde \\
\hline \multicolumn{3}{|c|}{ Produtos com registro proibido } & Preta \\
\hline
\end{tabular}

Fonte: Adaptado de WHO, 1990; OPS/WHO, 1996 - apud Peres, 1999.

Segundo Peres (1999), tão polêmica quanto a discussão sobre os possíveis danos ambientais e à saúde é a discussão acerca da nomenclatura correta para tais produtos. Outro 
entrave para a compreensão referente ao grau de toxidade dos produtos por parte dos agricultores são questões como: problemas de escolaridade, falta de esclarecimento, de orientação e técnica adequada. A indiscriminada utilização dos agrotóxicos é evidenciada por alguns fatores como: facilidade nas importações; entrada clandestina desses produtos no país; isenções fiscais concedidas à produção de agrotóxicos; concessão de crédito agrícola vinculada à utilização de agroquímicos e ações de indústrias químicas multinacionais para liberação e consumo dos mesmos. Logo, é possível perceber as enormes desigualdades sociais e regionais, bem como os riscos que esses produtos significam (DUTRA \& SOUZA, 2017; YE et al., 2017).

No Brasil cabe aos Ministérios da Agricultura, Pecuária e Abastecimento, Saúde e do Meio Ambiente avaliar, dentro de suas respectivas competências, os agrotóxicos em relação ao uso e riscos. No caso da saúde, cabe à ANVISA que executa desde 2000, essa tarefa. É importante relatar os obstáculos a que este órgão está sujeito com a pressão exercida por grandes corporações transnacionais, sendo muitas vezes impedido de realizar suas atribuições fundamentais, no cuidado com a saúde da população. Essas limitações têm afetado a saúde dos brasileiros. Neste cenário, as flexibilizações impostas pelos interesses de empresas, cujas atividades têm colaborado sistematicamente para a negligência socioambiental (VEIGA, 2007; ANVISA, 2010).

Uma importante informação sobre os riscos para saúde é o grande número pessoas intoxicadas por agrotóxicos de uso agrícola. Tais dados encontram-se disponíveis no pequeno ensaio cartográfico sobre o uso de agrotóxicos no Brasil, que expõe casos notificados por municípios entre o período 2007-2014. Outra contribuição da autora é reportada no estudo sobre a Geografia do uso de agrotóxicos no Brasil e conexões com a União Europeia (BOMBARDI 2016; 2017). De acordo com autora, no que diz respeito aos dados, para cada caso de intoxicação notificado, podem existir outros cinquentas não notificados. Logo, pode existir uma subnotificação da ordem de 1 para 50, ou seja, os dados apresentados estão relacionados apenas aos que foram notificados e isto pode representar um sério problema a ser avaliado.

No Estado do Rio de Janeiro especificamente, o consumo de agrotóxico é considerado alto (PERES \& MOREIRA, 2003). A publicação da Empresa Brasileira de Pesquisa Agropecuária sobre o panorama da contaminação ambiental por agrotóxicos origem agrícola no Brasil relata que a região serrana do Rio de Janeiro convive com constantes situações de risco de contaminação ambiental. Entre os exemplos estão os casos de Paty do Alferes na produção de tomates, com contaminação encontrada em torno de $70 \%$ em dois pontos hídricos pesquisados. Em Nova Friburgo, foram detectados agrotóxicos e alguns rios com impactos para a fauna local. Em outro ponto de amostragem as concentrações dessas substâncias estavam oito vezes acima do limite permitido pela legislação brasileira (GOMES \& ROBSON, 2014).

No caso da floricultura devido à fragilidade das flores, as quantidades de pulverizações dos agrotóxicos costumam ser ainda maiores, representando sérios riscos por exposição (RODRIGUES et al., 2010). Portanto, discutir a situação da população exposta aos agrotóxicos é urgente, devido aos possíveis danos ambientais e a saúde por exposição ocupacional, que geralmente trazem como desdobramentos, problemas sociais encontrados no meio rural (MARCATO, 1999; GARCÍA-GARCÍA et al., 2016).

\section{Impactos dos agrotóxicos em humanos, animais e meio ambiente.}

De acordo com Manual de Vigilância da Saúde de Populações Expostas a Agrotóxicos, as intoxicações podem ser classificadas em três níveis: aguda, subaguda e crônica. A aguda é caracterizada por sintomas que surgem rapidamente passadas algumas horas de contato com produtos alta ou extremamente tóxicos. Essa intoxicação ocorre de forma grave ou moderada, dependendo da quantidade de produto absorvido, e os sinais de contaminação são bem nítidos. A subaguda acontece quando uma pessoa tem contato pequeno ou moderado com produtos alta 
ou medianamente tóxicos e os sintomas são difíceis de serem percebidos e fáceis de confundir, como dor de cabeça, fraqueza, mal-estar, dores no estômago e sonolência. A contaminação crônica se dá quando um indivíduo é exposto de forma moderada aos produtos. Nesses casos os sintomas podem se manifestar após meses ou anos, com danos até irreversíveis à saúde (OPAS, 1996).

A dificuldade para diagnosticar intoxicações por agrotóxicos é um enorme obstáculo a se transpor, uma vez que os efeitos subagudos são difíceis de identificar e os crônicos são ainda mais complexos para se fechar um diagnóstico com precisão. Principalmente quando a exposição ocorre por longos períodos, os sintomas muitas vezes são considerados corriqueiros e facilmente confundidos. A contaminação por agrotóxicos pode ocorrer de forma direta (através do manuseio dos insumos na aplicação dos mesmos) ou indireta, (por meio de resíduos que permanecem nos alimentos). Entre as causas importantes listadas e relacionadas à intoxicação por agrotóxicos estão: fragilidade na fiscalização, ineficiência no papel das empresas quanto a falta de treinamento; não uso de equipamento de proteção individual (EPI); não uso do receituário agronômico; uso excessivo do produto; uso de produtos proibidos; presença de crianças e adolescentes em áreas contaminadas; ausência de articulação institucional, etc. (REEVES et al., 1999; YARPUZ-BOZDOGAN, 2018).

Importante esclarecer que os agrotóxicos estão entre as mais distintas substâncias detectadas em diferentes matrizes ambientais e possui a capacidade de promover desregulação endócrina. Entre os produtos apontados com potencial estrogênico estão: produtos de higiene pessoal, farmacêuticos e fitoterápicos, nanomateriais, drogas ilícitas, esgotos industriais e domésticos, entre outros. Neste caso, a grande inquietação por parte dos estudiosos está relacionada ao fato que durante a produção de agentes químicos, muitos não chegam a ser devidamente submetidos a testes toxicológicos básicos e podem representar sérios agravos ambientais (RODIL, 2012; SODRÉ et al., 2010).

Em relação a presença dos os compostos desreguladores endócrinos no ambiente, a United States Environmental Protection Agency (USEPA) propõe uma definição que reflete a diversidade de mecanismos envolvidos na perturbação do sistema endócrino:

Um interferente endócrino é um agente exógeno que interfere na síntese, secreção, transporte, ligação, ação ou eliminação de hormônios naturais que são responsáveis pela manutenção da homeostase, reprodução, desenvolvimento ou comportamento. Podem alterar diretamente a função de um órgão endócrino; interagir com um receptor de hormônios ou alterar o metabolismo de um hormônio em um órgão endócrino (USEPA, 1997).

Desreguladores endócrinos são produtos químicos hormonalmente ativos e capazes de interferir no sistema endócrino humano e de animais (KUMAR et al., 2012). Além dos efeitos no desenvolvimento e na reprodução, há também uma crescente preocupação com distúrbios metabólicos. A rota de contaminação pode ocorrer através de ingestão, excreção e uso tópico por humanos e animais dessas substâncias, que atingem diversos ecossistemas. Pesquisas em todo o mundo vêm se empenhando no desenvolvimento de métodos analíticos suficientemente sensíveis, com limites de detecção desses compostos em diferentes matrizes ambientais (SMITH et al., 2016). A dificuldade para compreender a forma de atuação dos desreguladores tem incentivado o desenvolvimento de técnicas analíticas eficientes para identificar e quantificar substâncias com potenciais estrogênicos em matrizes ambientais complexas (SILVA \& COLLINS, 2011). Frente a necessidade de melhor conhecimento dos potenciais efeitos dos compostos desreguladores endócrinos, aumentou a demanda pela validação de métodos de ensaios biológicos in vitro $e$ in vivo, que permitam identificar os efeitos da variedade de substâncias naturais e sintéticas presentes no ambiente (LOCATELLI et al., 2016). 
Os riscos para a vida animal estão associados a uma extensa gama de produtos químicos capazes de interferir no sistema endócrino de animais selvagens, incluindo aves, peixes, mamíferos, répteis e moluscos (WAYE \& TRUDEAU, 2011; HSIEH et al., 2013). Os efeitos vão desde diminuição na eclosão de ovos, feminização de machos, masculinização de fêmeas, além da condição de impossex; alterações no sistema imunológico de mamíferos marinhos e até diminuição ou extinção de populações inteiras. Estudos relatam que até $40 \%$ das doses ministradas de estrógenos sintéticos podem ser disponibilizadas para os ecossistemas (COSTA et al., 2014).

Em humanos alguns sintomas associados às mulheres incluem o aumento de cânceres, endometriose, puberdade precoce, ovário policístico e alterações em fetos no útero, alterações na tireóide entre outros (FERNÁNDEZ et al., 2010; BLANCO-MUÑOZ et al., 2016). Em homens adultos a maior incidência observada é de anormalidade em órgãos sexuais, diminuição na contagem média de espermatozóides e risco de desenvolver câncer nos testículos e próstata (BIRKETT \& LESTER, 2003; GHISELLI; JARDIM, 2006). Outros importantes dados associados aos humanos são síndrome metabólica, complicações pulmonares e cardiovasculares, além de problemas psicológicos (HATCH et al., 2010; NICOLOPOULOUSTAMATI et al., 2016).

Em função do seu potencial de periculosidade, a presença de agrotóxicos no ambiente pode afetar muitos organismos vivos e não simplesmente as pragas agrícolas. Desse tipo de contaminação resultam os mais variados problemas como: poluição do solo, da água e do ar, entre outros, uma vez que após a pulverização, as partículas de agrotóxicos em suspensão podem ser carregadas pelo vento para longas distâncias e posteriormente depositadas no solo. Assim, a água da chuva que lavou a superfície da folhagem infiltra os resíduos. Esses resíduos podem também interagir com as fases sólida, líquida e gasosa da água e com a porção viva do solo, ou seja, com a microbiota, provocando a quebra da matéria orgânica presente no solo (TOMITA\& BEYRUTH, 2002). Esse processo pode afetar ainda os cursos das águas superficiais e causar a contaminação de lençóis freáticos. Pesquisadores do tema apontam que entre os agroquímicos mais utilizados estão os organofosforado e os carbamatos, que em razão do seu alto poder letal tanto para animais quanto para humanos, inclusive por pessoas que desejam cometer suicídio (PEREIRA, 2004; MINEAU, 2018).

O mercado mundial de flores vem apresentando um crescimento vertiginoso desde a década de 1990, tornando-se um dos segmentos econômicos de grande importância para a organização mundial do comércio, com o cultivo de flores em todo mundo movimentando bilhões de dólares. Especificamente, o Estado do Rio de Janeiro desponta como segundo maior produtor de flores do país, com cultivo e comercialização de flores e plantas ornamentais apresentando expressiva transformação e contribuição para o agronegócio regional (NEVES \& PINTO, 2015). Assim sendo, há grandes obstáculos para conscientização sobre os riscos na utilização de agroquímicos, pois esbarra no desafio de conciliar produção com um cultivo sustentável.

\section{RESULTADOS E DISCUSSÃO}

Os dados coletados nas comunidades agrícolas de Vargem Alta, Bocaina dos Blaudts e Benfica, permitiram melhor compreensão sobre o processo de vida e a relação com o trabalho dos agricultores e familiares. Outra importante contribuição neste contato, foram os diálogos com os agentes de saúde e com os técnicos da EMATER de Nova Friburgo. As informações obtidas através de conversas informais e da observação do cotidiano, apontaram que para os agricultores, a compreensão sobre os riscos a que estão expostos no manuseio dos agrotóxicos é pequena. As colocações mais contundentes dos moradores, principalmente de Vargem Alta, estavam mais centradas em questões econômicas. De acordo com a maioria dos entrevistados, 
a partir do desenvolvimento da floricultura na localidade, a vida melhorou muito, possibilitando aquisição de bens, como eletrodomésticos, motos, carros, bem como compra ou melhoria das casas. O entusiasmo por parte dessa comunidade, que outrora vivia com pouquíssimos recursos, pode estar fundamentado no fato da produção de flores têm gerado bons rendimentos e retorno financeiro relativamente rápido, dependendo do produto (JUNQUEIRA \& PEETZ, 2007; NEVES \& PINTO, 2015). Cabe pontuar que Vargem Alta está localizada em área de difícil acesso, contando com apenas um posto de saúde e dificuldade de locomoção para Nova Friburgo, cidade mais próxima onde encontram-se maiores recursos econômicos e de saúde.

Os produtos mais citados no combate das pragas foram das marcas ${ }^{1}$ Pólo ${ }^{\circledR}$, Vertimeck®, Trigard® entre outros. Conforme relatos esses produtos são bastante empregados. Quando perguntado sobre o uso do equipamento de proteção individual durante as aplicações, as respostas foram que esses equipamentos são onerosos, reduzem os lucros no plantio, de difícil manutenção, de vida útil curta e dificultam a realização das atividades na lavoura. Quanto à forma de aquisição dos agrotóxicos, os entrevistados informaram que pode ser realizada sem receituário. E mesmo que os produtos venham acompanhados de receituários, existe dificuldade em compreendê-los. Nesse contexto, a não compreensão desses receituários pode estar relacionada à baixa escolaridade, à falta de fiscalização e de orientação técnica, entre outros fatores.

Em relação à gestão dos resíduos químicos e descarte das embalagens, os mesmos acreditam ser de responsabilidade dos agrônomos e vendedores. As embalagens vazias são reutilizadas para mistura de produtos com diferentes princípios químicos (as caldas), para armazenar as flores que serão vendidas. Essas embalagens são guardadas ao redor das casas e ficam até ao alcance de crianças, animais ou deixadas no próprio local de produção, potencializando assim os riscos a exposições. A realidade no cotidiano dessa comunidade na produção de flores reflete os sérios riscos de poluição ambiental como contaminação dos mananciais, pelo fato de algumas propriedades possuírem culturas muito próximas aos corpos d'água. Na Figura 3 podem ser visualizados alguns dos riscos por exposição em Vargem Alta. $\mathrm{Na}$ foto (A) Agricultor trabalhando sem o equipamento de proteção individual (EPI); (B) Córrego utilizado na irrigação exposto à contaminação; (C) Reutilização inadequada das embalagens (D) Descartes impróprios.

\footnotetext{
${ }^{1}$ Agrotóxicos fabricados pela empresa Syngenta Proteção de Cultivos Ltda.
} 
Figura 3 - Riscos por exposição em Vargem Alta

A)

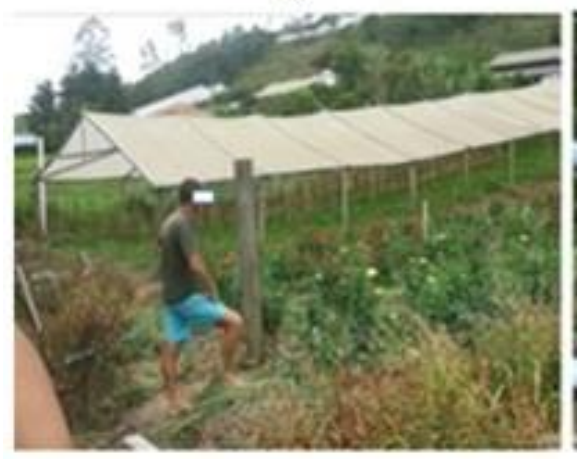

C)

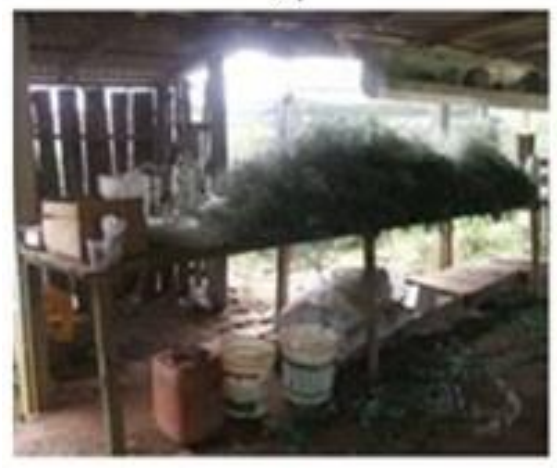

B)

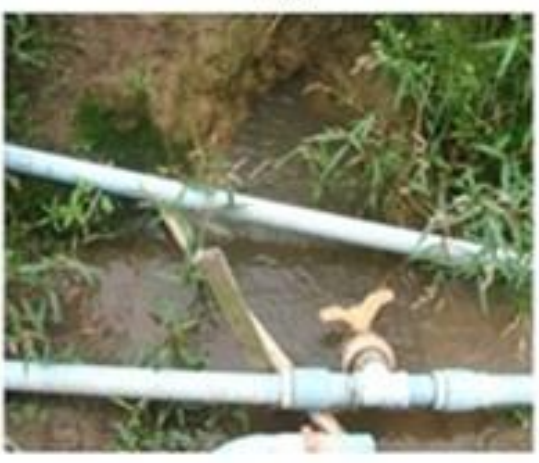

D)

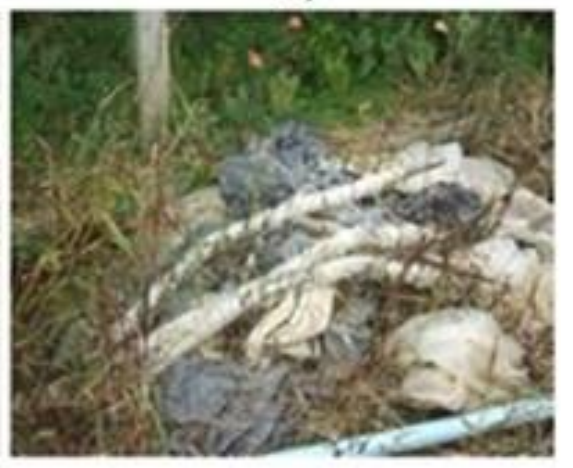

Fonte: Arquivo pessoal.

Os principais sintomas e queixas observados nos moradores de acordo com os agentes de saúde foram: dores de cabeça, tonturas, vômitos, processos alérgicos, hipertensão, diabetes, problemas de nervos, hepáticos, respiratórios, diarréias, dores no corpo, vertigens e desmaios. Todos estes sintomas estão devidamente cadastrados nos postos de saúde locais. Os casos mais graves como câncer, problemas endócrinos, hepáticos, depressão, entre outros, recebem registro e são encaminhados para o hospital de Nova Friburgo e adjacências.

Além dos sintomas relatados, outra questão preocupante são os casos de suicídio em Vargem Alta e nas comunidades agrícolas próximas. Além de adoecimento por exposição associação a problemas de nervos, existem casos de ingestão de agrotóxicos para suicídio. Durante a pesquisa, apenas em Vargem Alta foram seis casos. Um entrevistado compartilhou que em sua família, o pai faleceu de problemas cardíacos atribuídos ao uso de inseticidas, um sobrinho de 19 anos e o cunhado de 45 cometeram suicídio ingerindo agrotóxicos. Além da irmã de 37 anos faleceu por problemas hepáticos e depressão profunda. Alguns dados encontrados neste trabalho, condizem com o estudo desenvolvido por (ARAÚJO et al., 2007; CONTI et al., 2018).

As notificações fornecidas pelo Sistema Nacional de Informações TóxicoFarmacológicas (SINITOX), Ministério da Saúde/FIOCRUZ. Apenas entre 1999 e 2009 as intoxicações no Brasil por agrotóxico em áreas agrícolas, foram de 62 mil, com cerca de 5.600 intoxicações por ano, equivalendo a uma média de 15,5 intoxicações diárias, ou uma a cada 90 minutos. Nesse período, ocorreram 25.350 tentativas de suicídio notificados, uma média de 2.300 tentativas de suicídio por ano, ou, 6 tentativas de suicídio por dia por ingestão de agrotóxicos. Nestes casos, os próprios produtos servem como a arma para dar fim à própria vida, devido a transtornos psíquicos como depressão e ansiedade (MEYER et al., 2007; BOCHNER, 2007). Segundo pesquisas existe uma relação direta entre distúrbios psiquiátricos e exposição aos pesticidas, com danos muitas vezes irreversíveis, como neuropatia tardia por 
excessiva exposição principalmente a organofosforados, além de déficits significativos neurocomportamentais e anormalidades no sistema nervoso (ARAÚJO et al., 2007).

Recentemente, em ensaio cartográfico sobre o uso de agrotóxicos no Brasil, Bombardi (2016) expôs que o impacto do uso de agrotóxicos no país, no período de 2007 a 2014, foi de 1186 casos de morte por intoxicação, com cerca de 148 por ano e 1 a cada 2 dias e meio. $\mathrm{Na}$ faixa etária de 0 a 14 anos no mesmo período, foram 2181 casos de crianças intoxicadas e 300 dessas crianças entre 10 e 14 anos tentaram suicídio. Além de bebês de zero a menos de um ano de idade, intoxicados por agrotóxicos. Desse modo, estudos no Brasil e no exterior demonstram a conexão entre tentativa de suicídio e exposição crônica a alguns agrotóxicos (GUNNELL \& EDDLESTON, 2003; ROBIN, 2008; FARIA et al.,2014; LORANN \& CHERYL, 2016). Esses dados alarmantes deixam claro a perversão inserida na falácia do incentivo à utilização dos "defensivos agrícolas", para a qualidade de vida e apontam os graves perigos por exposição para as futuras gerações. Especialmente, porque a presença de subprodutos de pesticidas e a exposição cumulativa a pesticidas multiresidentes precisam ser igualmente pesquisados (MNIF et al., 2011).

Mediante os agravos dentro da lógica produtivista de incentivo ao uso abusivo de agrotóxicos é fundamental ratificar a urgência no debate aprofundado acercade um novo modo de pensar a agricultura (JARDIM et al., 2000; MENDEZ et al., 2018). Principalmente porque os riscos de resíduos de agrotóxicos seja em alimentos ou na floricultura deve ser considerado uma preocupação ambiental global. Neste caso, existe uma demanda bastante urgente no que se refere a implementação de programas de monitoramento de resíduos de pesticidas e de educação ambiental para agricultores sobre a produção comercial na floricultura, bem como nas demais produções agrícolas, a fim de prevenir, minimizar e reduzir a exposição aos agroquímicos (DONGA \& EKLO, 2018).

\section{CONSIDERAÇÕES FINAIS}

Conforme registros e análise das entrevistas em Vargem Alta foi possível perceber que a utilização de agrotóxicos é expressiva, sob pressão da lógica de mercado e atrativos baseados no marketing das grandes corporações fabricantes dessas substâncias. A falta de auxílio técnico adequado e a dificuldade na identificação e origem dos produtos, agregada ao descompasso entre as medidas mínimas de segurança, colaboram para incentivar o mito do poder dos agrotóxicos como remédios.

As queixas de sintomas mais citados pelos moradores e agentes de saúde de Vargem Alta foram: dores de cabeça, tonturas, vômitos, processos alérgicos, hipertensão, diabetes, problemas respiratórios, problemas de nervos, diarréias, dores no corpo; vertigens e desmaios. Segundo os profissionais de saúde. Os casos mais graves como câncer, problemas hepáticos e cardíacos entre outros, são encaminhados aos hospitais mais próximos.

Os resultados obtidos demonstrama necessidade de mais estudos sobre a ocorrência, o destino e o impacto de desreguladores endócrinos como os agrotóxicos. Além de análises específicas na água e solo. Cabe pontuar que há um longo caminho a ser percorrido no combate a permissividade em relação ao uso de agrotóxicos no Brasil. Muitos deles já proibidos na Europa e nos Estados Unidos por estarem relacionados a vários riscos para a saúde humana e ambiental.

Logo, pesquisas que contemplem os determinantes socioambientais e de saúde em áreas agrícolas como Vargem Alta são muito relevantes. Nesse sentido, este trabalho pode se constituir em mais uma contribuição na identificação de lugares e situações de risco para o desenvolvimento de ações de prevenção, mitigação, promoção de saúde e redução das desigualdades sociais em áreas rurais. 


\section{Agradecimentos}

Os autores agradecem à CAPES e a Secretaria Nacional de Portos pelo apoio financeiro.

\section{REFERÊNCIAS}

ABDEL-KHALEK, A. A. Chronic exposure to water of lake qaroun induced metal-related testicular damage and endocrine disruption in male fish. Biol Trace Elem Res.18;1-8, 2017.

AGÊNCIA NACIONAL DE VIGILÂNCIA SANITÁRIA (ANVISA). Seminário Mercado de Agrotóxicos e Regulação. Brasília, 2010. Disponível em: <http://portal.anvisa.gov.br/wps/content/AnvisaPortal/Anvisa/Inicio/AgrotoxicoseToxicologia /Assuntos+de+Interesse/Informes/20100322>. Acesso em: 24 ago.2017.

ALENTEJANO, P. R. R. As relações campo-cidade no Brasil do século XXI. Terra Livre, ano 19, v. 2, n. 21, p. 25-39, jul./dez. 2003.

ALTIERI, M. A.; NICHOLLS, C. I. Conversión agroecológica de sistemas convencionales de producción: teoría, estrategias y evaluación. Ecossistemas, v. 16, n. 1, p. 3-12, jan. 2007.

ARAÚJO, A.J. et al. Exposição múltipla a agrotóxicos e efeitos à saúde: estudo transversal em amostra de 102 trabalhadores rurais, Nova Friburgo, RJ. Ciência \& Saúde Coletiva, v. 12, n. 1, p. 115-130, 2007.

BARBOSA, L. C. A. Os pesticidas, o homem e o meio ambiente. Belo Horizonte: Ed. UFV, 2004.

BAUER, M; GASKELL, G. Pesquisa qualitativa com texto, imagem e som: um manual prático. 13. ed. Petrópolis, RJ: Vozes, 2015.

BILA, D. M; DEZOTTI, M. Desreguladores endócrinos no meio ambiente: efeitos e consequências. Química Nova, v.30, n. 3, p.651-666, 2007.

BIRKETT, J. W.; LESTER, J. N. Endocrine disrupters in wastewater and sludge treatment process. Boca Raton, FL: Lewis Publisher, 2003.

BLANCO-MUÑOZ, J; Lacasaña, M; López-Flores, I; Rodríguez-Barranco, M; GonzálezAlzaga, B; Bassol, S; Cebrian, M. E; López-Carrillo, L; Aguilar-Garduño, C. Association between organochlorine pesticide exposure andthyroidhormones in floricultureworkers. Environmental Research. Volume 150, pages 357-363, 2016.

BOCHNER, R. Sistema Nacional de Informações Tóxico-Farmacológicas SINITOX e as intoxicações humanas por agrotóxicos no Brasil. Ciência \& Saúde Coletiva, v.12, n.1, p. 7389, 2007.

BOGER, B; TONIN, F. S; ZAMORA, P. G. P; WAGNER, R; GOMES, E. C. Micropoluentes emergentes de origem farmacêutica em matrizes aquosas do Brasil: uma revisão sistemática. Ciência e Natura, v. 37, n. 4, p. 725-739, 2015. 
BOMBARDI, L. M. Agrotóxicos e agronegócio: arcaico e moderno se fundem no campo brasileiro. In: MERLINO, T.; MENDONÇA, M. L. (Org.). Direitos humanos no Brasil 2012: relatório da Rede Social de Justiça e Direitos Humanos. São Paulo: Expressão Popular, 2012. p. 75-85.

Pequeno ensaio cartográfico sobre o uso de agrotóxicos no Brasil. São Paulo: Laboratório de Geografia Agrária - USP; Blurb, 2016.

Geografia do uso de Agrotóxicos no Brasil e conexões com a União Europeia. FFLCH, USP, 296 p, 2017.

BRAIBANTE, E. F; ZAPPE, J. A. A química dos agrotóxicos. Química Nova na Escola, v. 34, n. 1, p. 10-15, fev. 2012.

BRITO, A. S. Manual de Ensaios Toxicológicos in vivo. Campinas: UNICAMP, 1994.

CARNEIRO, F. F; RIGOTTO, R. M; AUGUSTO, L.G..S; FRIEDRICH, K; BÚRIGO, A. C. Dossiê ABRASCO - Um alerta sobre os impactos dos agrotóxicos na saúde. Parte 1 Agrotóxicos, segurança alimentar e saúde. Rio de Janeiro: ABRASCO, 2015.

CARNEIRO, M. J. Descendentes de suíços e alemães de Nova Friburgo: de "colonos" a "jardineiros da natureza". In: GOMES, A. C. (Org.). Histórias de imigrantes e de imigração no Rio de Janeiro. Rio de Janeiro: 7 Letras. p. 44-65, 2000.

CARSON, Rachel. Primavera Silenciosa. São Paulo: Editora Melhoramentos, 1969.

CASTELO BRANCO, M. Avaliação do conhecimento do rótulo dos inseticidas por agricultores em uma área agrícola do Distrito Federal. Horticultura Brasileira, v. 21, n. 3, p. 570-573, 2003.

CASTRO, C. E. F. A floricultura no Brasil. In: CASTRO, C. E. F. et al. Manual de Floricultura. Maringá: Universidade Estadual de Maringá, 1992. p. 1-11.

CHAIM, A. História da pulverização. Jaguariúna, SP: Embrapa Meio Ambiente, 1999.

ClARO, D. P; SANTOS, A. C; ALENCAR, E; ANTONIALli, L. M; LiMA, J. B. O complexo agroindustrial das flores do Brasil e suas peculiaridades. Organizações rurais e agroindustriais. Revista de Administração, Lavras, v. 1, n.2, p. 17-31, 1999.

COLBORN, T; DUMANOSKI, D; MYERS, J. P. O futuro roubado. Porto Alegre: L\&PM, 2002.

CONTI, C. L; BARbOSA, W. M; SIMÃO, J. B. P; ÁlVARES DA SILVA, A. M. Pesticide exposure, tobacco use, poor self-perceived health and presence of chronic disease are determinants of depressive symptoms among coffee growers from Southeast Brazil. Psychiatry Research, Volume 260, Pages 187-192, 2018.

COSTA, E. M. F; SPRITZER, P. M.; HOHL, A; BACHEGA, T. A. S. S. Efeitos dos desreguladores endócrinos no desenvolvimento do trato reprodutivo feminino. Arquivos Brasileiros de Endocrinologia \& Metabologia, v. 58, n. 2, mar. 2014. 
D'AMATO, C.; TORRES, J. P. M.; MALM, O. DDT (diclorodifeniltricloroetano): toxicidade e contaminação ambiental - uma revisão. Química Nova, v. 25, n. 6, p. 995-1002, 2002.

DOMINGUES, B. Proteção para quem? Saúde se preocupa com os efeitos dos agrotóxicos no Brasil, o maior consumidor dessas substâncias no mundo. RADIS: Comunicação em Saúde, n. 95, p. 11-15, jul. 2010.

DONGA, T. K; EKLO, O. M. Environmental load of pesticides used in conventional sugarcane production in Malawi. Crop Protection, Volume 108, P: 71-77, 2018.

DUTRA, R. M. S; SOUZA, M. M. O. Impactos negativos do uso de agrotóxicos à saúde humana. Hygeia,v. 13, n. 24, p. 127-140, 2017.

FARIA, N. M. X.; FASSA, A.C.G.; MEUCCI, R. D. Association between pesticide exposure and suicide rates in Brazil. Neuro Toxicology, v. 45, p. 355-362, 2014.

FERNÁNDEZ, M. et al. Neonatal exposure to bisphenol $A$ and reproductive and endocrine alterations resembling the polycystic ovarian syndrome in adult rats. Environmental Health Perspectives, v. 118, n. 9, p. 1217-1222, 2010.

GARCÍA-GARCÍAC. R; PARRÓN, T; REQUENA, M; ALARCÓN, R; TSATSAKIS, A. M; HERNÁNDEZ, A. F. Occupational pesticide exposure and adverse health effects at the clinical, hematological and biochemical level. Life Sciences, Volume 145, P: 274-283, 2016.

GHISELLI, G.; JARDIM, W. F. Interferentes endócrinos no ambiente. Química Nova, v. 30, n. 3, p. 695-706, 2006.

GOMES, M. A. F; ROBSON, R. M. B. Panorama da contaminação ambiental por agrotóxicos e nitrato de origem agrícola no Brasil: cenário 1992/2011. Meio Ambiente, 2014, 35 p. (Documentos / Embrapa Meio Ambiente; 98). Disponivel https://www.infoteca.cnptia.embrapa.br/bitstream/doc/987245/1/Doc98.pdf. Acessado em abril de 2018.

GUNNELL, D.; EDDLESTON, M. Suicide by intentional ingestion of pesticides: a continuing tragedy in developing countries. International Journal of Epidemiology, v. 32, n. 6, p. 902909, 2003.

HSIEH, C.Y; YANG L; KUO W. C; ZEN, Y. P. Efficiencies of freshwater and estuarine constructed wetlands for phenolic endocrine disruptor removal in Taiwan-Science of the Total Environment 464:182-191, 2013.

HATCH, E. E. et al. Association of endocrine disruptors and obesity: perspectives from epidemiological studies. International Journal of Andrology, v. 33, n. 2, p. 324-332, 2010.

INSTITUTO BRASILEIRO DE GEOGRAFIA E ESTATÍSTICA (IBGE). Dados de produção agrícola 2010. Brasília, 2010. Disponível em: http://www.ibge.gov.br. Acesso em: jul. 2017. 
Censo agropecuário: resultados preliminares 2006. Disponível em: http://www.ibge.gov.br.Acesso em dez. 2008.

IÑIGUEZ ROJAS, L.; TOLEDO, L.M. (Org.). Espaço e doença: um olhar sobre o Amazonas. Rio de Janeiro: FIOCRUZ, 1998.

JALLOW, M. F. A; AWADH, D. G; ALBAHO, M. S; DEVI, V. Y; THOMAS, B. M. Pesticide risk behaviors and factors influencing pesticide use among farmers in Kuwait. Science of The Total Environment, Volume 574 (1) P: 490-498, 2017.

JARDIM, I.C.S.F; ANDRADE, J.A.; QUEIROZ, S. C. N. Resíduos de agrotóxicos em alimentos: uma preocupação ambiental global - um enfoque às maçãs. Química Nova, v. 32, n. 4, p. 996-1012, 2009.

JUNQUEIRA, A. H.; PEETZ, M. S. Exportação de flores e plantas ornamentais $25 \%$ maiores em 2007: análise conjuntural das exportações brasileiras de flores e plantas ornamentais no primeiro bimestre de 2007. Hórtica Consultoria e Treinamento, São Paulo, 2007. Disponível em: <http:www.hortica.com.br/artigos/Export_bim01_2007.pdf>. Acesso em: 14 ago.2017.

KASSOUF, A. L. Acesso aos serviços de saúde nas áreas urbana e rural do Brasil. Revista de Economia e Sociologia Rural, v.43, n.1, p.29-44, jan/mar. 2005.

KIM, K. H; KABIR, E; JAHAN, S. A. Exposure to pesticides and the associated human health effects. Science of The Total Environment, V 575, Pages 525-535, 2017.

KRUVE, A; HERODES, K; LEITO, I. Accounting for matrix effects of pesticide residue liquid chromatography/electrospray ionisation mass spectrometric determination by treatment of background mass spectra with chemometric tools. Rapid Communications in Mass Spectrometry, v. 25, n. 9, p. 1159-68, 2011.

KUMAR, A; PRASAD, M. N. V; SYTAR, O. Lead toxicity defence strategy and associated indicative biomarkes in Talium triangulare grown hydroponica. Chemosphere, v.89, p.1056-1065, 2012.

LI, Z; JENNINGS, A. Global variations in pesticide regulations and health risk assessment of maximum concentration levels in drinking water. Journal of Environmental Management, Volume 212, Pages 384-394, 2018.

LOCATELLI, M. et al. Analytical methods for the endocrine disruptor compouns determination in environmental water samples. Journal of Chromatografy A, v. 1434, p. 1$18,2016$.

LORANN, S.; CHERYL, L. B. Assessing the connection between organophosphate pesticide poisoning and mental health: a comparison of neuropsychological symptoms from clinical observations, animal models and epidemiological studies. Cortex, v. 74, p. 405-416, 2016.

MARCATO, C. Agricultura sustentável: alguns conceitos e princípios. 1999. Disponível em:<https://permacoletivo.files.wordpress.com/2008/05/cartilha-agricultura-sustentavel.doc>. Acesso em: 31 jan. 2018. 
MAZOYER, M.; ROUDART, L. História das agriculturas no mundo: do neolítico à crise contemporânea. São Paulo: Editora Unesp, 2010.

MELO, S. A. S; TROVÓ, A. G; BAUTITZ, I. R; NOGUEIRA, R. F.P. Degradation of residual pharmaceuticals by advanced oxidation processes. Química Nova, v. 32, n.1, p. 88197, 2009.

MENDEZ, A; CASTILLO, L. E; RUEPERT, C; HUNGERBUEHLER, K; NG, C. C. Tracking pesticide fate in conventional banana cultivation in Costa Rica: A disconnect between protecting ecosystems and consumer health. Science of The Total Environment. Volumes 613-614, Pages 1250-1262, 2018.

MEYER, T. F; RESENDE, I. L. C; ABREU, J. C. Incidência de suicídios e uso de agrotóxicos por trabalhadores rurais em Luz (MG), Brasil. Revista Brasileira de Saúde Ocupacional, São Paulo, v. 32, n. 116, p. 24-30, jul/dez. 2007.

MINEAU, G. P. Organophosphorous and Carbamate Insecticides: Impacts on Birds. Reference Module in Earth Systems and Environmental Sciences Encyclopedia of the Anthropocene, V 5, p. 105-109, 2018.

MNIF, W; HASSINEA, I. H; BOUAZIZ, A; BARTEGI, A; THOMAS, O; ROIG, B. Effect of endocrine disruptor pesticides: a review. International Journal of Environmental Research and Public Health, v. 8, n. 6, p. 2265-2303, 2011.

MOREIRA, J. C; JACOB J. C; PERES P; LIMA, J. S; MEYER, A; OLIVEIRA SILVA, J. J; SARCINELLI, P. N; BATISTA, D. F; EGLER, M; FARIA, M. V. C; ARAUJO, A. J; KUBOTA, A. H; SOARES, M. O; ALVES, S. R; MOURA, C. M; CURI, R. Avaliação integrada do impacto do uso de agrotóxicos sobre a saúde humana em uma comunidade agrícola de Nova Friburgo, RJ. Ciência \& Saúde Coletiva, v.7, n. 2, p.299-311, 2002.

NEGINTAJI, A; SAFAHIEH, A; ZOLGHARNEIN, H; MATROODI, S. Short-term induction of vitellogenesis in the immature male yellowfin seabream (Acanthopagrus latus) exposed to bisphenol A and 17 ß-estradiol. ToxicolInd Health, 34(2):119-27, 2018.

NEVES, M. F; PINTO, M. J. A. (Org.). Mapeamento e quantificação da cadeia de flores e plantas ornamentais do Brasil. São Paulo: OCESP, 2015. Disponível em: <http://www.ibraflor.com/publicacoes/vw.php?cod248. Acesso em: 25 março 2018.

NICOLOPOULOU-STAMATI, P; MAIPAS, S; KOTAMPASI, C; STAMATIS, P; HENS, L Chemical pesticides and human health: the urgent need for a new concept in agriculture. Frontiers in Public Health, v. 4, art. 148, 2016.

OLIVEIRA-SILVA, J.J.et al. Influence of socioeconomic factors on the pesticides poisoning, Brazil. Revista de Saúde Pública, v. 35, n. 2, p. 130-135, 2001.

ORGANIZAÇÃO PAN-AMERICANA DA SAÚDE (OPAS). Manual de vigilância da saúde de populações expostas a agrotóxicos. Brasília: OPAS/Ministério da Saúde, 1996..Disponívelem: http://bvsms.saude.gov.br/bvs/publicacoes/livro2.pdf. Acesso em: 20 mar. 2018. 
PEREIRA, J. L. G. Entre o campo e a cidade: amizade e ruralidade segundo jovens de Nova Friburgo. Estudos Sociedade e Agricultura, v. 12, n. 2, p. 322-352, out. 2004.

PERES, F. É veneno ou é remédio? Os desafios da comunicação rural sobre agrotóxicos. 1999. Dissertação (Mestrado)-Escola Nacional de Saúde Pública, Fiocruz, Rio de Janeiro, 1999.

Saúde, trabalho e ambiente no meio rural brasileiro. Ciência \& Saúde Coletiva, Rio de Janeiro, v. 14, n. 6, p. 1995-2004, 2009.

PERES, F; MOREIRA, C. J. É Veneno ou é remédio?Agrotóxicos, saúde e ambiente. Rio de Janeiro: FIOCRUZ, 2003.

PORSERYD, T; KELLNER, M; REYHANIAN, C. N; VOLKOVA, K; ELABBAS, L, ULLAH, S; OLSÉN, H; DINNÉTZ, P; HÃLLSTRÕM, I. Combinatory effects of low concentrations of $17 \alpha$-etinylestradiol and citalopram on non-reproductive behavior in adult zebrafish (Danio rerio). Aquat. Toxicol, 193:9-17, 2017.

REEVES, M; SCHAFER, K; HALLWARD, K; KATTEN, A. Campos envenenados: lostrabajadores agrícolas y los pesticidas em California. Resumen executivo. San Francisco, CA: CPR, 1999. Disponível em: 〈http://www.bvsde.paho.org/tutorial2/fulltex/campos.pdf〉. Acesso em: 12 fev. 2018.

ROBIN, M. M. O mundo segundo a Monsanto. São Paulo: Radical Livros, 2008.

RODIL, R.; QUINTANA, J. B.; CELA, R. Oxidation of synthetic phenolic antioxidants during water chlorination. Journal of Hazardous Materials, v. 199-200, p. 73-81, 2012.

RODRIGUES, A. P. M. S.; MENDONÇA JÚNIOR, A. F.; MESQUITA, H. C. Uso de agrotóxicos na floricultura. ACSA -Agropecuária Científica no Semi-Árido, v. 6, n. 4, p. 23 27, out/dez. 2010.

SÁ REGO, V. V. B. Mundos em confronto: o desenvolvimento do Capitalismo e a educação numa comunidade camponesa. Dissertação (Mestrado em Educação) - Pontifícia Universidade Católica do Rio de Janeiro, Rio de Janeiro, 1988.

SANTOS, M. Técnica, espaço, tempo: globalização e meio técnico-científico informacional. São Paulo: HUCITEC, 1994.

SILVA, C. G. A.; COLLINS, C. H. Aplicações de cromatografia líquida de alta eficiência para o estudo de poluentes orgânicos emergentes. Química Nova, v. 34, n. 4, p. 665-676, 2011.

SILVA, G. B.; BOTELHO, M. I. V. O processo histórico da modernização da agricultura no Brasil (1960-1979), Campo-Território. Revista de Geografia Agrária, v. 9, n. 17, p. 362387, 2014.

SMITH, A. J; MCGOWAN, T; DEVLIN, M.J; MASSOUD, M. S; AL-ENEZI, M; ALZAIDAN, A. S; AL-SARAWI, H. A; LYONS, B. P. Screening for contaminant hotspots in the marine environment of Kuwait using ecotoxiccological and chemical screening techniques. Marine Pollution Bulletin, v. 100, n. 2, p. 681-688, 2016. 
SODRÉ, F. F; PESCARA, I. C; MONTAGNER, C.C; JARDIM W. F. Assessing selected estrogens and xenoestrogens in Brazilian surface waters by liquid chromatographytandem mass spectrometry. Microchemical Journal, v. 96, n. 1, p. 92-98, 2010.

TAMAI, M. A; LOPES, R. B; ALVES, S. B. Manejo de Pragas na Floricultura. In: Reunião Itinerante de Fitossanidade do Instituto Biológico. Mogi das Cruzes - SP. Anais. Campinas - SP: Instituto Biológico (IB), p. 77-82, 2000. Disponível em http://www.homologa.biologico.sp.gov.br/rifib/IIIRifib/66-70.pdf. Acesso em: 20/07/2018.

TOMITA, R. Y; BEYRUTH, Z. Toxologia de agrotóxicos em ambientes aquáticos. $\mathrm{O}$ Biológico, São Paulo, v. 64, n. 2, p. 135-142, 2002.

UNITED STATES ENVIRONMENTAL PROTECTION AGENCY (USEPA). EPA's Report on the Environment (Roe Final Report). Washington, D. C. National Center for Environmental Assessment, 2008. EPA/600/R-07/045F. Disponível em: http://www.epa.gov/roe. Acesso em: 02 Jan. 2018.

VEIGA, M. M. Agrotóxicos: eficiência econômica e injustiça socioambiental. Ciência \& Saúde Coletiva, v. 12, n. 1, p. 145-152, 2007.

WAYE, A.; TRUDEAU, V. L. Neuroendocrine disruption: more than hormones are upset. Journal of Toxicology and Environmental Health, Part B, v. 14, n. 5-7, p.270-291, 2011.

WORLD HEALTH ORGANIZATION(WHO). The recommended classification of pesticides by hazard and guidelines to classification 1990-1991. Disponível em: http://whqlibdoc.who.int/hq/1990/WHO_PCS_90.1_REV.1.pdf. Acessado abril, 2018.

YARPUZ - BOZDOGAN, N. The importance of personal protective equipment in pesticide applications in agriculture. Current Opinion in Environmental Science \& Health. Volume 4, Pages 1-4, 2018.

YE, M; BEACH, J; MARTIN, J.W; SENTHILSELVAN, A. Pesticide exposures and respiratory health in general populations. Journal of Environmental Sciences, Volume 51, Pages 361-370, 2017. 